\title{
Análise e localização de centros de armazenamento e triagem de resíduos sólidos urbanos para a rede de logística reversa: um estudo de caso no município de São Mateus, ES
}

\author{
Giovane Lopes Ferria, Gisele de Lorena Diniz Chaves ${ }^{\mathrm{b}}$, Glaydston Mattos Ribeiro ${ }^{\mathrm{c} *}$ \\ agiovaneferri@hotmail.com, UFES, Brasil \\ bgiselechaves@ceunes.ufes.br, UFES, Brasil \\ c*glaydston@pet.coppe.ufrj.br, UFRJ, Brasil
}

\begin{abstract}
Resumo
A falta de planejamento de muitas cidades brasileiras face ao crescimento da população urbana e da economia gerou impactos diretos na infraestrutura de serviços. Entre os serviços afetados está o de coleta de resíduos sólidos urbanos (RSU), que adotou os chamados “lixões” como solução imediata, causando sérios impactos ambientais. Entretanto, o aumento de RSU motivou o governo a promover a Política Nacional de Resíduos Sólidos, que tem como objetivos, entre outros, acabar com os lixões até 2014 e implantar a coleta seletiva, a logística reversa e a compostagem dos resíduos úmidos no Brasil. Aterros sanitários deverão ser projetados e viabilizados por meio da coleta seletiva. Assim, este artigo apresenta uma metodologia baseada em um modelo matemático de localização de centros de armazenamento e triagem de RSU para municípios que permite centralizar os resíduos em uma espécie de centro de distribuição reverso, para agrupar os RSU coletados. Um estudo de caso foi realizado no município de São Mateus, ES, para ilustrar todo o processo de obtenção e utilização dos dados, o que torna o modelo mais próximo da realidade e os resultados mais precisos, auxiliando efetivamente a tomada de decisão pelos gestores públicos.
\end{abstract}

Palavras-chave

Resíduos sólidos urbanos. Logística reversa. Localização de facilidades.

\section{Introdução}

Nos últimos cinquenta anos, o Brasil alterou sua característica de país agrário para outra, predominantemente urbana. Segundo o Instituto Brasileiro de Geografia e Estatística - IBGE (2010), cerca de $85 \%$ da população brasileira estava concentrada em áreas urbanas em 2010.

0 crescimento das cidades brasileiras não aconteceu de forma planejada, o que impactou a infraestrutura de serviços urbanos, tais como o sistema de gestão dos resíduos sólidos. Uma solução imediatista para esse problema foi o descarte dos resíduos sólidos urbanos nos vazadouros a céu aberto, os chamados "lixões". No entanto, esses locais não possuem tratamento do chorume ou controle dos gases de efeito estufa produzidos em sua decomposição, o que causa sério impacto ambiental.

Com o crescimento da economia do país, esse problema foi agravado, pois é sabido que aumentos da produção e do consumo impactam diretamente na geração de Resíduos Sólidos Urbanos (RSU). Portanto, a concentração da população nas cidades e o crescimento econômico, que acarretam em aumento da geração de RSU, motivaram o governo a promover estrutura legal para impulsionar um aumento na capacidade de manejar e gerenciar esse resíduo.

Apesar do incentivo legal e de uma maior sustentabilidade ambiental, a mudança na destinação do lixo gerado no país não tem acompanhado o 
aumento na geração de RSU, o que aumenta a destinação inadequada dos resíduos destinados. Houve um aumento de 2,5\% na quantidade de RSU coletados em 2011, mas apesar de todo esforço de ampliação na cobertura dos serviços de coleta de RSU no país, 6,4 milhões de toneladas de RSU deixaram de ser coletadas no ano de 2011 e, por consequência, tiveram destino impróprio (Associação Brasileira de Empresas de Limpeza Pública e Resíduos Especiais, 2011, p. 30).

A Política Nacional de Resíduos Sólidos - lei n. 12.305 (Brasil, 2010), promulgada em 2010, normaliza a prestação dos serviços públicos de limpeza urbana e manejo de resíduos sólidos. Acabar com os lixões até 2014 e implantar a coleta seletiva, a logística reversa e a compostagem dos resíduos úmidos, objetivos estabelecidos por essa lei, são desafios para o poder público e para o setor privado no país e, em especial, para os municípios, titulares dos serviços de limpeza pública. Aterros sanitários deverão ser projetados e viabilizados por meio da coleta seletiva. Segundo essa norma legal, a União só pode firmar convênios e contratos para o repasse de recursos federais para estados e municípios, em ações relacionadas com esse tema, se eles tiverem formulado seus planos de gestão de resíduos sólidos (Brasil, 2012).

Para os municípios, os desafios para alterar a realidade são diversos, mas ressalta-se a capacidade de planejamento e de gestão mais eficiente dos serviços públicos. Nesse sentido, este artigo propõe uma metodologia baseada em um modelo matemático de localização de centros de armazenamento e triagem de RSU para municípios que permite centralizar os resíduos em uma espécie de centro de distribuição reverso para agrupar os RSU coletados. Um estudo de caso foi realizado no município de São Mateus, localizado na região norte do estado do Espírito Santo, para ilustrar todo o processo de obtenção e utilização dos dados.

Essa estratégia se justifica, pois o aumento no volume de resíduos coletados proporciona ganhos produtivos pelo aumento da escala. Dessa forma, um volume maior de resíduos viabiliza a aquisição e instalação de equipamentos, bem como a especialização dos armazéns em função dos diversos tipos de materiais e torna viável o transporte de resíduos não passíveis de reciclagem na região. Centros de triagem que permitem a separação dos materiais passiveis de serem reciclados promovem tanto uma redução no custo de transporte do RSU até o aterro como prolongam a vida útil dele. Dessa forma, eliminam-se custos relacionados ao descarte final dos RSU e agrega-se valor por meio do aproveitamento dos materiais recicláveis.
Além da melhoria de aspectos ambientais, os centros de triagem proporcionam benefícios sociais pela integração dos catadores ao processo. A centralização dos materiais e consequente aumento no volume de resíduos tende a facilitar as negociações comerciais para compra e venda de materiais recicláveis, pois é possivel estruturar e formalizar processos de compra e venda em maior escala. Com isso, as associações e cooperativas aumentam a variedade de resíduos com potencial comercial de reciclagem e sua inserção nos mercados e, consequentemente, seus rendimentos.

Assim, embora o modelo matemático utilizado seja baseado na literatura disponível sobre localização de facilidades, este estudo é original por envolver aspectos reais do município de São Mateus e integrar tanto o aspecto social dos catadores quanto a necessidade de melhorias na gestão dos resíduos por meio de uma visão mais técnica do assunto, com aplicação prática. Este estudo considera parâmetros que influenciam o custo de instalação dos centros de triagem, mas não somente eles. Considera também instalações já existentes de associações de catadores de material reciclável e restrições para a instalação desse tipo de empreendimento, o que influencia positivamente em sua aplicação prática.

0 restante deste artigo está estruturado como segue: na seção 2 é apresentada uma breve revisão bibliográfica associada à localização de facilidades e coleta de resíduos. A seção 3 apresenta o modelo matemático utilizado. A obtenção de dados para o funcionamento do modelo é apresentada na seção 4. Testes computacionais são apresentados na seção 5. Por último, a seção 6 apresenta as conclusões.

\section{Localização de facilidades e logística reversa - uma breve revisão}

Os problemas de localização de facilidades consistem em determinar locais, normalmente a partir de um conjunto de locais candidatos, para a instalação de facilidades que atendam às demandas de clientes, otimizando uma função que envolve custo. 0 termo "facilidades" é utilizado para representar, por exemplo, postos de saúde, centros de reaproveitamento, escolas, fábricas, antenas etc., enquanto "clientes" refere-se, por exemplo, a bairros, unidades de vendas, estudantes etc. Localizar ou alocar facilidades é uma importante decisão estratégica a ser tomada por organizações privadas ou públicas (Owen \& Daskin, 1998; Ribeiro \& Arroyo, 2008).

A literatura disponível sobre localização de facilidades é bastante extensa e envolve conceitos e aplicações práticas que utilizam modelos matemáticos. Lopez \& Henderson (1989), Ballou (2001) e 
Bhatnagar et al. (2003) indicam que diversos fatores (tangiveis e intangíveis) influenciam na localização de facilidades. Por exemplo, para localização de centros de varejo, Ballou (2001) afirma que os seguintes fatores influenciam no processo:

- Demografia local, base populacional e renda potencial;

- Fluxo de tráfego e acessibilidade, número e tipos de veículos, número e tipos de pedestres, disponibilidade de transporte público, fácil acesso às vias principais e nível de congestionamento;

- Estrutura do varejo, disponibilidade, número e tipos de concorrentes e de lojas na área, lojas complementares vizinhas, proximidade de áreas comerciais e promoções conjuntas por comerciantes locais;

- Características do ponto, proximidade e qualidade do estacionamento, visibilidade, tamanho e forma do ponto, qualidade de entradas e saídas e boas condições dos edifícios existentes; e

- Fatores legais e de custo, tipo de zoneamento, períodos e cláusulas restritivas de locação, impostos locais, serviços e manutenção.

Percebe-se assim que existem vários e complexos fatores envolvidos no processo de localização, sendo muitos deles conflitantes. Dessa forma, taxonomias possibilitaram classificar os problemas de localização, conforme pode ser visualizado no trabalho de Krarup \& Pruzan (1990). Para esses autores, os problemas de localização de facilidades podem ser classificados em modelos planares, modelos discretos, modelos estáticos e dinâmicos, modelos determinísticos e estocásticos, modelos com um único produto e modelos multiprodutos, modelos com um único objetivo e modelos multiobjetivos, modelos capacitados e não capacitados.

Descrever essas classificações não é o objetivo deste trabalho, porém destacam-se os modelos discretos capacitados multiprodutos, como o proposto por Geoffrion \& Graves (1974), que busca localizar centros de distribuição de carga. 0 modelo matemático proposto pelos autores considera um conjunto de locais de produção (plantas), um conjunto de produtos, um conjunto de locais candidatos para os centros de distribuição (facilidades) e um conjunto de clientes que demandam produtos (pontos de demanda). Além disso, o modelo considera a capacidade de fornecimento de cada produto em cada planta, volumes mínimo e máximo, passando pelas facilidades, custos fixos de instalação e custos variáveis, que são função das quantidades transportadas. Com isso, busca-se localizar os centros de distribuição de carga ao menor custo possivel, tal que todo cliente seja atendido e que as restrições de capacidade sejam respeitadas.
A partir do trabalho de Geoffrion \& Graves (1974), outros autores incorporam novas características e, assim, novas aplicações/modelos surgiram, como pode ser visto nos trabalhos de Love et al. (1988), Pirkul \& Jayaraman (1998), Chiyoshi et al. (2000), Barcelos, Pizzolato \& Lorena (2004), Corrêa \& Lorena (2006), Dubke (2006) e Goetschalckx (2011).

Envolvida nesse contexto está a logística reversa que se refere a atividades dedicadas à coleta ou recuperação de produtos (Dekker et al., 2004; Adlmaier \& Sellito, 2007; Hernandez et al., 2012; Araujo et al., 2013). Como indicado por Melo et al. (2009), três fatores podem ser mencionados para justificar as atividades reversas: aspectos econômicos (possibilidade de recuperar valor de produtos usados), leis governamentais e pressões dos consumidores. Ainda de acordo com Melo et al. (2009), as facilidades dentro da logística reversa podem ser de dois tipos: centros de coleta (instalações que recebem produtos usados) e locais de recuperação/remanufatura (instalações onde os produtos são recondicionados/remanufaturados). Além dessas, uma terceira facilidade envolvida na rede de logística reversa são os locais de disposição final dos produtos, ou seja, instalações onde os produtos ou materiais são incinerados ou descartados. Nesse contexto, a estrutura da rede de distribuição é estendida para contemplar fluxo de retorno dos clientes para os locais de reparo, de recondicionamento ou de destino final apropriado.

Por último, uma revisão mais extensa sobre problemas de localização e logística reversa pode ser obtida em Fleischmann et al. (1997), Erengüç et al. (1999), Cunha \& Caixeta Filho (2002), Jayaraman et al. (2003), Klose \& Drexl (2005), Revelle et al. (2008), Melo et al. (2009) e Pizzolato et al. (2012).

Com base nos conceitos acima e nas características identificadas no estudo de caso apresentado neste artigo verifica-se a necessidade de um modelo de localização de facilidades que considere faixas de capacidade e custos fixos de instalação e de operação associados às faixas de capacidade. Existe, assim, uma inter-relação entre a teoria de localização e a teoria de logística reversa, ambas exploradas neste artigo para propor a localização de centros de armazenagem e triagem de RSU no município de São Mateus, ES, conforme seção 3.

\section{Modelagem matemática}

No que se refere à destinação final do RSU, a nível Brasil, segundo dados do IBGE (Instituto Brasileiro de Geografia e Estatística, 2008), por intermédio da Pesquisa Nacional de Saneamento Básico, 50,8\% dos municípios possuem vazadouros a céu aberto como 
destino. Quando se refere ao estado do Espírito Santo, esse percentual é ainda maior, chegando a 66,7\%, de acordo com Secretaria de Estado de Saneamento, Habitação e Desenvolvimento Urbano (SEDURB) do estado do Espírito Santo. 0 município de São Mateus está incluído nesses percentuais, pois possui como único meio de destinação final de RSU um vazadouro a céu aberto, ou "lixão", localizado no bairro Pedra D'agua. A coleta é realizada por uma empresa privada que utiliza seis caminhões compactadores sem nenhum tipo de separação, que despejam todo o material coletado no local citado anteriormente.

A coleta seletiva foi implantada pela prefeitura do município apenas no bairro Aviação, realizada através de caminhões baú, os quais efetuam o transporte dos materiais até uma cooperativa já existente no município, localizada no bairro Vitória, porém, nenhum dado relativo a essa iniciativa foi fornecido. Essa coleta seletiva foi descontinuada e, segundo informações do secretário de obras e infraestrutura do município, um edital será lançado ainda em 2013 com as indicações de parâmetros de funcionamento da coleta seletiva para o município, em atendimento à legislação atual.

A rede de logística reversa proposta neste artigo para gerenciar os RSU no município de São Mateus, ES, envolve a inserção de centros de armazenagem e triagem pelo município com o objetivo de segregar os materiais passíveis de serem reciclados antes de enviar os RSU para o aterro sanitário, que será construído em atendimento à legislação vigente, conforme proposto na Figura 1.
Anteriormente, esse RSU era coletado e enviado diretamente ao lixão localizado na periferia da cidade. Como o aterro sanitário será construído em consórcio com outros municípios da região norte do Espírito Santo, sua localização se dará em um ponto facilitador (em termos de distância e acessibilidade, além de outros fatores como atendimento às exigências legais, disponibilidade e custo do terreno) e mais distante do centro do município de São Mateus. Portanto, centros de armazenagem e triagem de RSU se justificam pela diminuição do volume de resíduos destinados ao aterro, reduzindo os custos de transporte e aumentando a vida útil do aterro sanitário, além de permitirem a comercialização de materiais passíveis de serem reciclados. Segundo D'Almeida \& Vilhena (2000), para longas distâncias é recomendado o uso de estações de transferência que limitem o percurso de veículos coletores, os RSU são transferidos para veículos maiores que fazem o transporte até o local de disposição final.

No entanto, a determinação do local de instalação do aterro, bem como a indicação de possíveis locais para recuperação ou reciclagem de materiais, ou de locais com opções de descarte distintas (tais como destruição de produtos perigosos), não foi incorporada neste trabalho, apesar de proposto na rede de logística reversa da Figura 1. Essa escolha foi motivada pelo anseio de garantir a obtenção de um modelo de localização baseado em dados reais do município de São Mateus. A determinação do local de instalação do aterro sanitário segue, além dos fatores já citados, aspectos políticos envolvendo os demais
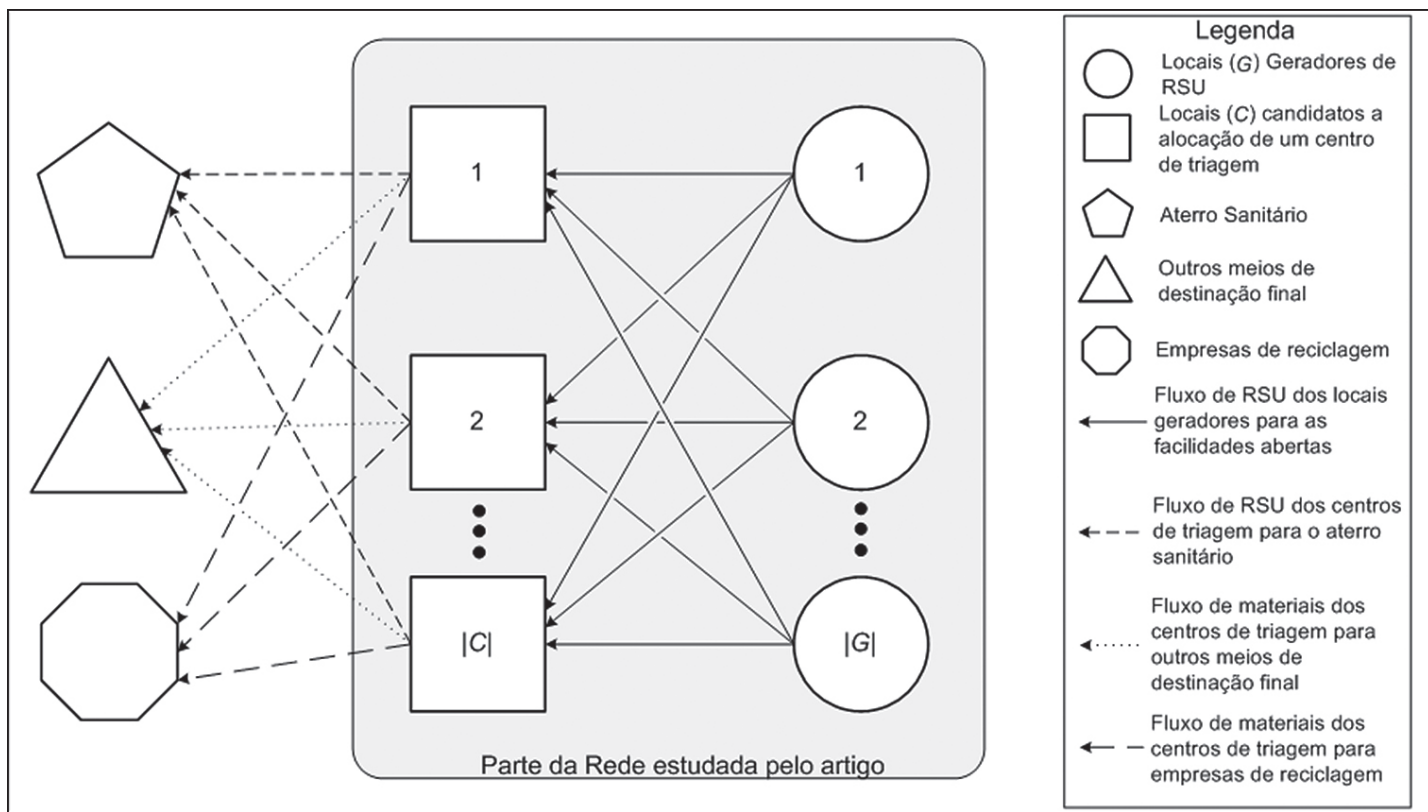

Figura 1. Proposta de rede de logística reversa para RSU no município de São Mateus. 
municípios do consórcio CONORTE (Espírito Santo, 2008). A possibilidade de inserção dessa facilidade na modelagem foi considerada, no entanto os parâmetros relacionados não foram fornecidos pela administração pública. Além disso, a inclusão de possíveis locais para recuperação ou reciclagem requer a indicação dos materiais a serem coletados e uma estimativa de volume de cada um deles, fatores que são influenciados por decisões e políticas da administração pública, tais como a coleta seletiva que ainda não abrange todo o município. A inserção desses elos na rede de logística reversa tornaria o modelo mais completo mas comprometeria o propósito de fornecer uma rede elaborada a partir de dados mais próximos da realidade. Essa inserção é uma etapa posterior na estruturação dessa rede de gerenciamento dos RSU.

Portanto, a rede de logística reversa definida neste estudo para o gerenciamento de RSU no município de São Mateus, ES, envolve, basicamente, dois atores: os locais geradores de RSU (bairros do município) e os locais candidatos a receberam as instalações de armazenagem e triagem de RSU, representados na área cinza da Figura 1.

Para atender às características encontradas no município de São Mateus, ES, o modelo matemático de localização necessário para representar o problema deve considerar faixas de capacidade e custos fixos de instalação e de operação associados às faixas de capacidade, pois muitos desses atributos são dependentes de outros fatores como, por exemplo, custo de aquisição do terreno, espaço disponível para equipamentos, maquinário necessário e equipe de colaboradores. A seção 4 apresenta detalhadamente todo o processo de estimação dos dados necessários e suas relações.

Dessa forma, considerando a revisão bibliográfica apresentada na seção 2 , seja $C$ o conjunto de locais geradores de resíduos e $C$ o conjunto de locais aptos a receberem um centro de armazenagem e triagem de resíduos sólidos. Seja ainda $K f$ um conjunto que representa as faixas de capacidade permitidas para as facilidades $j \in C$.

Para atender as necessidades do município de São Mateus, ES, todo RSU gerado no local $i \in G$, representado por $Q$, deve ser destinado a uma facilidade aberta $j \in C$. Entretanto, se uma facilidade $j \in C$ for aberta em uma dada faixa de capacidade $k$ $\in K f$, todo o RSU recebido por $j$ deverá estar dentro da sua faixa de capacidade. A faixa de capacidade $k \in K f$ para a facilidade $j$ apresenta limites inferior $\underline{K}_{j}^{k}$ e superior $\bar{K}_{j}^{k}$ que necessariamente precisam ser respeitados.

0 custo fixo de instalação de um centro de armazenagem e triagem varia de acordo com o local e com a faixa de capacidade escolhida para ele. Assim, seja $F I_{j}^{k}$ o custo fixo de instalação da facilidade $j \in C$ trabalhando na faixa de capacidade $k \in K f$. Como todo centro de armazenagem tem uma vida útil estimada em projeto, seja $t$ o parâmetro que a representa.

Similar ao custo fixo de instalação, o custo fixo de operação de uma facilidade varia conforme a faixa de capacidade escolhida para ela. Sendo assim, seja $F O_{j}^{k}$ o custo fixo de operação associada à facilidade $j \in C$ trabalhando na faixa de capacidade $k \in K f$.

Todo resíduo apresenta um custo de transporte para ser transportado do seu local de origem para um centro de armazenagem e triagem e normalmente esse custo depende da distância percorrida. Assim, seja $d_{i j}$ a distância entre o local $i \in G$ e a facilidade $j \in C$ e $v t_{i j}$ o frete entre o par de origem e destino $(i, j)$. Assim, seja $c_{i j}=v t_{i j} d_{i j}$ o custo unitário de transporte entre a origem $i \in G$ e destino $j \in C$.

Com relação às variáveis de decisão, seja:

- $l_{j}^{k} \in\{0,1\}$ uma variável binária que representa a abertura $\left(l_{j}^{k}-1\right)$ ou não $\left(l_{j}^{k}-0\right)$ da facilidade $j \in C$ na faixa de capacidade $k \in K f$; e

- $x_{i i} \geq 0$ uma variável que representa a quantidade de RSU enviada do local $i \in G$ para a facilidade aberta em $j \in C$.

Dessa maneira, a formulação matemática referente à localização de facilidades destinadas a promover a triagem de resíduos sólidos urbanos dentro do canal reverso para RSU no município é representada a seguir. Cabe ressaltar que essa modelagem matemática está baseada nos trabalhos de Geoffrion \& Graves (1974) e Jayaraman et al. (2003).

\section{Minimizar}

$$
v=\sum_{j \in C}\left[\left(\frac{F I_{j}}{t}\right)+F O_{j}\right]+\sum_{j \in C} \sum_{i \in G}\left(c_{i j} x_{i j}\right)
$$

Sujeito a:

$$
\begin{aligned}
& F O_{j}=\sum_{k \in K f} F O_{j}^{k} l_{j}^{k} \quad \forall j \in C \\
& F I_{j}=\sum_{k \in K f} F I_{j}^{k} l_{j}^{k} \quad \forall j \in C \\
& \sum_{k \in K f} l_{j}^{k} \leq 1 \quad \forall j \in C \\
& \sum_{k \in K f} \underline{\mathrm{K}}_{j}^{k} l_{j}^{k} \leq \sum_{i \in G} x_{i j} \leq \sum_{k \in K f} \overline{\mathrm{K}}_{j}^{k} l_{j}^{k} \quad \forall j \in C
\end{aligned}
$$

$\sum_{j \in C^{x}} x_{i j}=Q_{i} \quad \forall j \in G$

$l_{j}^{k} \in\{0,1\} \quad \forall j \in C, k \in K f$ 
$x_{i j} \geq 0 \quad \forall i \in G, j \in C$

$F I_{j} \geq 0 \quad \forall j \in C$

$F O_{j} \geq 0 \quad \forall j \in C$.

A função objetivo (1) está dividida em duas partes principais. A primeira representa os custos fixos totais, sendo eles subdivididos entre instalação e operação, e a segunda representa o custo total de transporte, o qual varia de acordo com a quantidade a ser transportada. As restrições (2) e (3) garantem, respectivamente, que os custos fixos de instalação e de operação de uma facilidade sejam obtidos conforme a faixa de capacidade em que ela foi aberta. As restrições (4) garantem a abertura de no máximo uma faixa de capacidade por facilidade aberta. As restrições (5) garantem que todo o resíduo enviado a uma facilidade aberta respeita a faixa de capacidade dela. Já as restrições (6) garantem que todo o resíduo gerado em um ponto de origem deve ser enviado às facilidades. Enquanto as restrições (7)-(10) estão associadas ao domínio das variáveis de decisão. Note que as variáveis de decisão definidas em (9) e (10) são auxiliares. Elas são utilizadas nas restrições (2) e (3) e na função objetivo (1).

\section{Obtenção dos dados para o modelo matemático}

A seguir é apresentada a metodologia utilizada para obtenção dos parâmetros do modelo (1)-(10) para o município de São Mateus, ES. Os experimentos computacionais realizados e os cenários avaliados são apresentados na seção 5 .

\subsection{Locais geradores de RSU, locais candidatos e custo unitário de transporte}

O município de São Mateus, ES, é composto de 39 bairros geradores de RSU, como mostra a Figura 2. Além disso, o município conta ainda com sete pequenos centros de armazenamento e triagem (cooperativas), que são gerenciados por catadores independentes de material reciclável. Existe uma cooperativa no bairro Universitário (vinculada ao Projeto Araçá), três no bairro Guriri (as cooperativas do Valdecir, do Magno e do Francisco), uma no bairro Bonsucesso (cooperativa do Primo), uma no bairro Ayrton Senna (cooperativa do Osmar) e outra no bairro Vitória (Projeto Reciclar).

Essas cooperativas, assim denominadas pelos autores do artigo, apesar de não possuírem registro formal, já possuem infraestrutura, recursos humanos

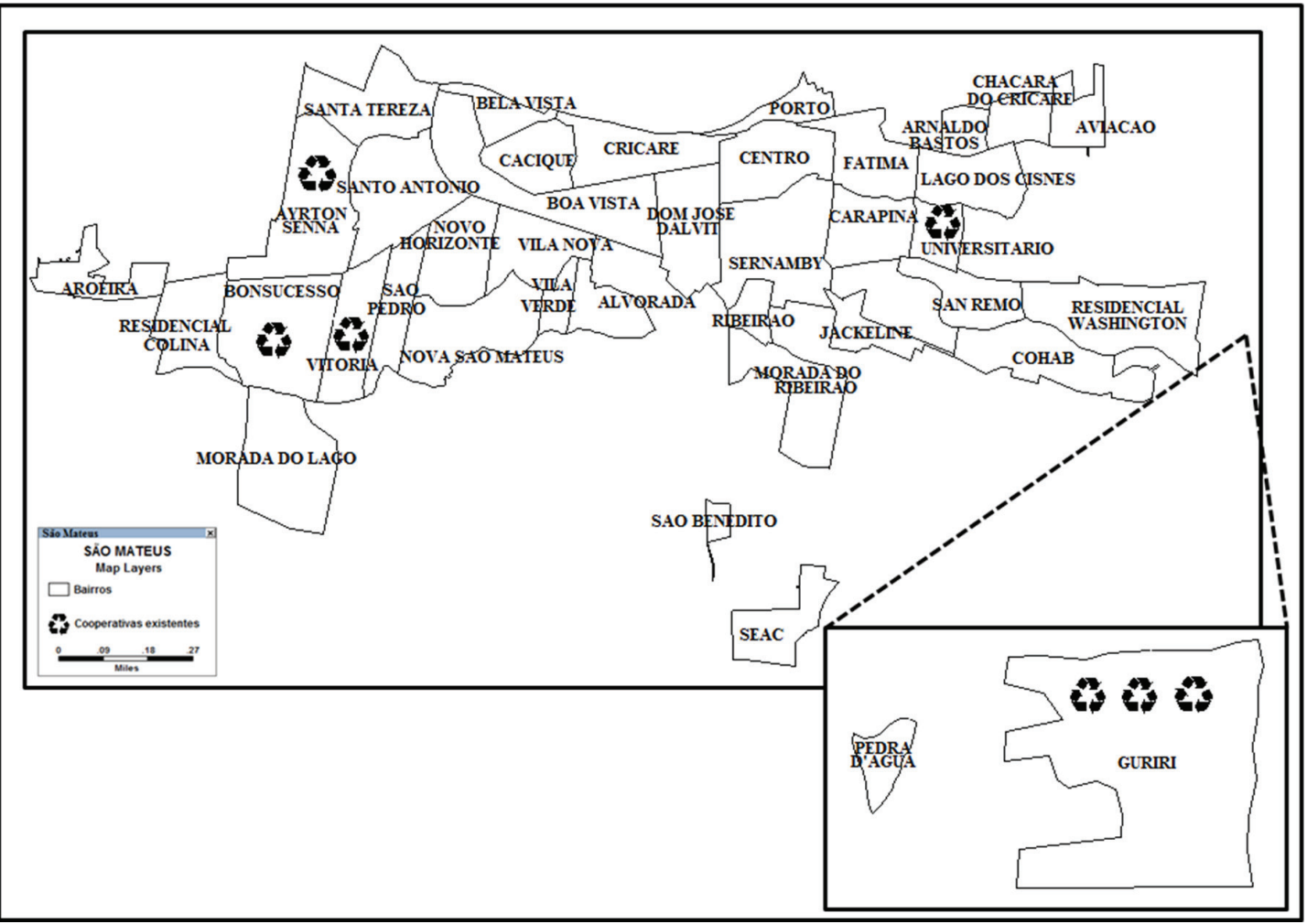

Figura 2. Mapa da área urbana de São Mateus, ES. 
e experiência na coleta e triagem de materiais, mesmo que essas atividades sejam realizadas de forma não estruturada e sem planejamento. Além de facilitarem a implantação dos centros de armazenagem e triagem do município, a inserção desses locais foi motivada, também, pela tentativa de evitar que grupos já envolvidos na coleta de resíduos, mesmo que de maneira informal, não fossem inseridos na rede de logística reversa, gerando um problema socioeconômico no município. Segundo Gouveia (2012), os catadores de materiais recicláveis (agrupados formalmente em cooperativas ou não) podem ser considerados os grandes protagonistas da gestão de resíduos sólidos no Brasil. Aquino et al. (2009), ao estudarem a cadeia produtiva reversa de pós-consumo da região da grande Florianópolis, SC, indicaram que quando os catadores se organizam em rede, os produtos podem ser comercializados diretamente com as indústrias recicladoras e que ganhos significativos podem ser obtidos.

Portanto, essa análise pode indicar a viabilidade efetiva de utilização desses locais como centros de armazenagem e triagem de RSU, bem como a faixa de capacidade ideal de cada um deles. Assim, considerando a notação apresentada na seção 3 , tem-se $|G|=39$ e $|C|=46$, onde $|\cdot|$ representa o tamanho do conjunto em análise.

Para que o parâmetro custo de transporte $c_{i j}$, $i \in G, j \in C$, seja definido, se faz necessário obter as distâncias entre os locais geradores $i$ e os locais candidatos $j$. Assim, dada a localização espacial dos centros econômicos dos bairros e das cooperativas, as distâncias Euclidianas foram obtidas entre todo $\operatorname{par}(i, j), i \in G, j \in C$ e, em seguida, foi corrigida em 10\%, conforme o trabalho de Pimentel (2004).

Com relação ao valor do frete, buscaram-se valores associados à utilização de caminhão toco baú como veículo de transporte. Esse tipo de veículo foi escolhido por caminhões compactadores não serem indicados quando se pretende, posteriormente, realizar a segregação de materiais para reciclagem (Massukado, 2004). Os veículos compactadores promovem a contaminação ou umidificação de materiais passíveis de serem reciclados, podendo inviabilizar sua recuperação. Nesse sentido, foi realizada uma visita à empresa responsável pela coleta seletiva no município de Belo Horizonte, MG, que utiliza esse veículo para transporte. Os dados de frete dessa empresa não puderam ser utilizados, pois, nesse caso, as viagens são de longas distâncias, sem paradas para completar a carga. Portanto, para atender o caso de São Mateus, ES, que exige paradas frequentes entre os bairros e no qual as distâncias são relativamente curtas, foram considerados os valores fornecidos por um encarregado operacional de uma transportadora da região. Esse responsável indicou que o frete deveria ser de $\mathrm{R} \$ 10,50$ por quilômetro por tonelada, ou seja, $v_{i j}=\mathrm{R} \$ 10,50 / \mathrm{km} /$ ton para todo $i \in G$ e $j \in C$. Assim, a matriz final de transporte não será aqui apresentada dadas as suas dimensões, entretanto pode ser disponibilizada mediante solicitação.

\subsection{Estimativa de RSU gerado}

Por falta de dados reais do município de São Mateus, ES, a quantidade de RSU gerada por bairro foi obtida com base na sua população. Segundo o lBGE (Instituto Brasileiro de Geografia e Estatística, 2010), a população total do município de São Mateus é de 110 mil habitantes. Portanto, com o objetivo de encontrar a população total de cada bairro, realizou-se um rateio da população de acordo com a área de cada bairro.

A Tabela 1 apresenta a quantidade de RSU coletado nos municípios do estado do Espírito Santo conforme o estudo Panorama dos Resíduos Sólidos Urbanos no Brasil 2011 Associação Brasileira de Empresas de Limpeza Pública e Resíduos Especiais (2011). Essa tabela correlaciona os parâmetros população urbana, quantidade de RSU coletado por dia e PIB (Produto Interno Bruto) per capita e permite identificar a quantidade de RSU produzida por habitante por dia, já que essa geração é função do porte e da distribuição de riquezas do município.

Como pode ser observado na Tabela 1, o município de São Mateus, ES, não foi incluído na pesquisa da ABRELPE (Associação Brasileira de Empresas de Limpeza Pública e Resíduos Especiais, 2011). Portanto, não se conhece a quantidade de RSU coletada nem o PIB per capita do município. Para obter a geração de resíduos de cada bairro, que depende da sua população e renda, obtiveram-se índices médios a partir da Tabela 1. Utilizou-se como critério o PIB per capita de $\mathrm{R} \$ 14.000,00$, já que esse valor é uma

Tabela 1. Quantidade de resíduos por habitantes no ES.

\begin{tabular}{lcccc}
\hline Municipio & $\begin{array}{c}\text { População } \\
\text { urbana } \\
\text { (x 1.000) }\end{array}$ & $\begin{array}{c}\text { Quantidade } \\
\text { de RSU } \\
\text { coletada } \\
\text { (ton/dia) }\end{array}$ & $\begin{array}{c}\text { PIB per } \\
\text { capita } \\
\text { (R\$) }\end{array}$ & $\begin{array}{c}\text { Per capita } \\
\text { (kg/hab/dia) }\end{array}$ \\
\hline Castelo & 21,9 & 26,0 & $9.622,24$ & 1,18 \\
Colatina & 99,0 & 80,0 & $15.485,14$ & 0,81 \\
Fundão & 14,6 & 18,0 & $11.883,65$ & 1,23 \\
João Neiva & 12,8 & 18,0 & $11.090,31$ & 1,41 \\
Linhares & 123,4 & 116,0 & $17.447,15$ & 0,94 \\
Sooretama & 17,2 & 14,4 & $11.073,54$ & 0,84 \\
Venda Nova & 15,0 & 11,9 & $11.613,92$ & 0,79 \\
do Imigrante & 417,8 & 460,0 & $14.608,82$ & 1,10 \\
Vila Velha & 330,5 & 342,0 & $61.790,59$ & 1,03 \\
Vitória & & & &
\end{tabular}

Fonte: adaptado de ABRELPE (Associação Brasileira de Empresas de Limpeza Pública e Resíduos Especiais, 2011, p. 134). 
mediana dos valores PIB per capita dos municípios do estado do Espírito Santo abordados na pesquisa da ABRELPE (Associação Brasileira de Empresas de Limpeza Pública e Resíduos Especiais, 2011). Além disso, no geral, os municípios que apresentaram um PIB per capita inferior a R \$ 14.000,00 apresentaram índices de geração de RSU maiores; e o contrário, os municípios com PIB per capita superior a R\$ 14.000,00, apresentaram índices médios de geração de RSU menores. Portanto, os municípios com PIB per capita abaixo desse valor caracterizam o grupo 1, que possui um índice médio de geração de RSU de $1,09 \mathrm{~kg} / \mathrm{hab} / \mathrm{dia}$. Para o grupo 2, esse índice foi de $0,97 \mathrm{~kg} / \mathrm{hab} / \mathrm{dia}$.

Assim, com a população estimada de cada bairro, fez-se uma estratificação deles com base no custo do terreno $\left(\mathrm{R} \$ / \mathrm{m}^{2}\right)$, obtido com o auxílio do órgão de cadastro imobiliário da prefeitura. Portanto, para estimar a quantidade de RSU gerada por bairro, considerou-se que para aqueles bairros nos quais o custo do terreno é de até $\mathrm{R} \$ 800,00$ por $\mathrm{m}^{2}$, o índice de geração de RSU indicado seria aquele estipulado para o grupo 1. Por outro lado, para os demais bairros deveria ser utilizado o índice do grupo 2. Considerou-se que essa análise é válida, pois observa-se que terrenos mais valiosos são adquiridos, na sua grande maioria, por pessoas com maior poder aquisitivo, caracterizando uma população à qual está associado, geralmente, um PIB per capita maior. Com isso, a Tabela 2 apresenta o total de RSU gerado por cada bairro.

\subsection{Faixas de capacidade}

As faixas de capacidade foram definidas com base em uma entrevista a um empresário da área de resíduos sólidos. Assim, foram criadas 12 faixas de capacidade, que foram dividas de maneira igualitária entre 1 e 43.800 toneladas por ano.

\subsection{Custo fixo de instalação e de operação}

0 custo fixo de instalação está associado aos custos de aquisição de terreno, de construção das instalações físicas, de aquisição de máquinas e equipamentos e de treinamentos do pessoal (Schwartz Filho, 2006). Portanto, esse custo aumenta se a capacidade desejada do centro de armazenagem e triagem aumentar, pois uma maior capacidade implica em um aumento da área utilizada, do número de maquinário e de funcionários.

Com os custos do terreno $\left(\mathrm{R} \$ / \mathrm{m}^{2}\right)$ de cada bairro fornecidos pelo cadastro imobiliário da prefeitura, corrigidos para os valores de mercado, obteve-se, novamente junto a um empresário da área de gestão de resíduos sólidos, dados referentes aos custos de
Tabela 2. Quantidade de RSU por bairro.

\begin{tabular}{|c|c|c|c|c|}
\hline $1 D^{*}$ & Bairro & $\begin{array}{l}\text { População } \\
\text { estimada } \\
\text { (hab) }\end{array}$ & $\begin{array}{c}\text { Índice médio } \\
\text { de geração } \\
\text { de RSU } \\
\text { (kg/hab/dia) }\end{array}$ & $\begin{array}{c}\text { Total de } \\
\text { RSU } \\
\text { (ton/ano) }\end{array}$ \\
\hline 1 & Aroeira & 2.940 & 1,09 & 1.170 \\
\hline 2 & Residêncial Colina & 2.940 & 1,09 & 1.170 \\
\hline 3 & Morada do Lago & 2.940 & 1,09 & 1.170 \\
\hline 4 & Ayrton Senna & 4.900 & 1,09 & 1.949 \\
\hline 5 & Bonsucesso 1, 11, 111 & 4.900 & 1,09 & 1.949 \\
\hline 6 & Vitória & 2.940 & 1,09 & 1.170 \\
\hline 7 & Santo Antônio & 3.920 & 1,09 & 1.560 \\
\hline 8 & Santa Tereza & 2.940 & 1,09 & 1.170 \\
\hline 9 & São Pedro & 980 & 1,09 & 390 \\
\hline 10 & Nova São Mateus & 2.940 & 1,09 & 1.170 \\
\hline 11 & Novo Horizonte & 980 & 1,09 & 390 \\
\hline 12 & Boa Vista & 4.900 & 0,97 & 1.735 \\
\hline 13 & Cacique & 1.960 & 1,09 & 780 \\
\hline 14 & Bela Vista & 980 & 1,09 & 390 \\
\hline 15 & Vila Nova & 2.940 & 1,09 & 1.170 \\
\hline 16 & Vila Verde & 980 & 1,09 & 390 \\
\hline 17 & Alvorada & 1.960 & 1,09 & 780 \\
\hline 18 & Cricaré & 2.940 & 1,09 & 1.170 \\
\hline 19 & Dom José Dalvit & 2.940 & 0,97 & 1.041 \\
\hline 20 & Centro & 2.940 & 0,97 & 1.041 \\
\hline 21 & Sernamby & 3.920 & 0,97 & 1.388 \\
\hline 22 & Ribeirão & 980 & 1,09 & 390 \\
\hline 23 & Fátima & 2.940 & 0,97 & 1.041 \\
\hline 24 & Porto & 980 & 1,09 & 390 \\
\hline 25 & Carapina & 2.940 & 0,97 & 1.041 \\
\hline 26 & SEAC & 1.960 & 1,09 & 780 \\
\hline 27 & São Benedito & 980 & 1,09 & 390 \\
\hline 28 & $\begin{array}{l}\text { Morada do } \\
\text { Ribeirão }\end{array}$ & 2.940 & 1,09 & 1.170 \\
\hline 29 & Jackeline & 1.960 & 1,09 & 780 \\
\hline 30 & Arnaldo Bastos & 1.960 & 1,09 & 780 \\
\hline 31 & Universitário & 1.960 & 0,97 & 694 \\
\hline 32 & Chacará do Cricaré & 1.960 & 1,09 & 780 \\
\hline 33 & Aviação & 1.960 & 1,09 & 780 \\
\hline 34 & Lago dos Cisnes & 2.940 & 1,09 & 1.170 \\
\hline 35 & San Remo & 1.960 & 1,09 & 780 \\
\hline 36 & Cohab & 3.920 & 1,09 & 1.560 \\
\hline 37 & $\begin{array}{l}\text { Residencial } \\
\text { Washington }\end{array}$ & 3.920 & 1,09 & 1.560 \\
\hline 38 & Pedra D’agua & 1.960 & 1,09 & 780 \\
\hline \multirow[t]{2}{*}{39} & Guriri & 12.000 & 0,97 & 4.249 \\
\hline & & & Total & 42.258 \\
\hline
\end{tabular}

*As cooperativas receberam números de identificação na seguinte ordem: 40 - bairro Universitário; 41, 42 e 43 - bairro Guriri; 44 - bairro Bonsucesso; 45 - bairro Ayrton Senna; e 47 - bairro Vitória.

instalação. Assim, conforme o especialista, verificou-se, por exemplo, que para um centro de armazenagem e triagem com capacidade de até 3.650 toneladas/ano se faz necessário um lote com uma área de $500 \mathrm{~m}^{2} \mathrm{e}$ a construção de um galpão no valor de $\mathrm{R} \$ 30.000,00$, a aquisição de uma prensa, um elevador, uma balança e algumas ferramentas, nos valores respectivos de $\mathrm{R} \$$ $15.000,00, R \$ 10.000,00, R \$ 5.000,00$ e $R \$ 5.000,00$. 
0 custo fixo de operação se refere ao custo dos salários e encargos dos funcionários, manutenção do local e dos equipamentos, gastos de luz, água e telefone (Schwartz Filho, 2006). Esse parâmetro também foi obtido por meio de entrevistas com empresários da região, que forneceram a quantidade necessária de funcionários para um centro de armazenagem e triagem de acordo com a sua capacidade, bem como o salário desses funcionários, os gastos com manutenção, pintura, energia, água, gás e telefone. Por exemplo, verificou-se que um centro de armazenagem e triagem com capacidade de até 3.650 toneladas/ano necessita de cinco funcionários, com salário aproximado de $\mathrm{R} \$ 746,00$ cada, um gasto de R\$3.000,00 com manutenção e pintura ao longo do ano e $\mathrm{R} \$ 600,00$ mensais destinados a energia, água, gás e telefone.

A Tabela 3 apresenta os custos fixos de instalação por bairro de acordo com a faixa de capacidade e na Tabela 4 estão os custos fixos de operação conforme as faixas de capacidade. Percebe-se que o bairro com o custo fixo de instalação mais elevado é o Centro, o que reflete os custos do terreno, em boa relação com a realidade: os custos da complexidade de se instalar uma facilidade em um local com maior densidade demográfica, tráfego de veículos e pedestres, além de restrições de movimentação deve ser mais alto.

Para considerar as cooperativas no processo de localização como possíveis candidatas a receberem os centros de armazenagem e triagem, utilizou-se como custo fixo de instalação apenas o custo de aquisição de novos equipamentos. Além disso, os limites de capacidade foram encontrados respeitando-se as capacidades reais, obtidas por meio de questionários, e os demais parâmetros foram iguais aos dos bairros em que cada ponto se encontrava. Não foi considerado o custo para aumento de capacidade dessas cooperativas, já que elas se encontram em locais em que essa expansão não seria possível. Portanto, a Tabela 3 apresenta apenas os custos de aquisição de novos equipamentos dentro das faixas de capacidade em que essas cooperativas podem operar.

Por fim, testou-se a relação entre o custo fixo das instalações e as faixas de capacidade, conforme demonstra o Figura 3. Percebe-se que, para os grupos analisados (agrupamentos de bairros com o mesmo custo fixo de instalação - Tabela 3), o comportamento da elevação dos custos em função da evolução das faixas de capacidade é não linear. Esse resultado é interessante, pois quando não se dispõe desses dados utilizam-se, normalmente, aproximações lineares. A busca por essas informações exige esforço, mas fornece resultados mais próximos da realidade.

\section{Localização dos centros de armazenagem e triagem: análise de cenários}

Para avaliar a localização dos centros de armazenagem e triagem de RSU no município de São Mateus, ES, cenários foram criados a partir das especificidades encontradas no município. Inicialmente, todos os bairros foram considerados aptos a receberem os centros, compondo o cenário 1. Em seguida, alguns cenários foram criados considerando-se a inserção das cooperativas já existentes no município, compondo o cenário 2, que visa tanto a redução do custo total quanto a inclusão social desses trabalhadores em um projeto formal. Além disso, alguns bairros foram removidos do conjunto de locais candidatos - cenário 3 - porque estão localizados na região central

Tabela 3. Custo fixo de instalação em R\$ (x 1.000).

\begin{tabular}{|c|c|c|c|c|c|c|c|c|c|c|c|c|}
\hline \multirow{2}{*}{$1 D^{*}$} & \multicolumn{12}{|c|}{ Faixa** } \\
\hline & 1 & 2 & 3 & 4 & 5 & 6 & 7 & 8 & 9 & 10 & 11 & 12 \\
\hline $\begin{array}{c}1,2,3,4,5,6 \\
8,9,11,13,14 \\
15,16,17,18 \\
24,26,27,38\end{array}$ & 103,91 & 136,41 & 207,82 & 240,32 & 311,73 & 344,23 & 415,64 & 448,14 & 519,55 & 552,05 & 623,46 & 655,96 \\
\hline $\begin{array}{c}22,28,33 \\
35,36\end{array}$ & 123,36 & 155,87 & 246,73 & 279,23 & 370,10 & 402,60 & 493,46 & 525,96 & 616,83 & 649,33 & 740,19 & 772,69 \\
\hline $\begin{array}{c}7,10,29,30 \\
32,34,37\end{array}$ & 142,82 & 175,32 & 285,64 & 318,14 & 428,46 & 460,96 & 571,28 & 603,78 & 714,10 & 746,60 & 856,92 & 889,42 \\
\hline $\begin{array}{c}12,19,21,23 \\
25,31\end{array}$ & 162,27 & 194,78 & 324,55 & 357,05 & 486,83 & 519,33 & 649,10 & 681,60 & 811,38 & 843,88 & 973,65 & $1.006,15$ \\
\hline 39 & 172,00 & 204,50 & 344,00 & 376,50 & 516,00 & 548,50 & 688,00 & 720,50 & 860,00 & 892,50 & $1.032,00$ & $1.064,50$ \\
\hline 20 & 210,91 & 243,41 & 421,82 & 454,32 & 632,73 & 665,23 & 843,64 & 876,14 & $1.054,55$ & $1.087,05$ & $1.265,46$ & $1.297,96$ \\
\hline $40,41,42,44$ & 35,00 & 35,00 & - & - & - & - & - & - & - & - & - & - \\
\hline 43,46 & 35,00 & 35,00 & 70,00 & 70,00 & - & - & - & - & - & - & - & - \\
\hline 45 & 35,00 & 35,00 & 70,00 & 70,00 & 105,00 & 105,00 & - & - & - & - & - & - \\
\hline
\end{tabular}

*Esse campo identifica o bairro conforme definido na Tabela 2; os identificadores de 40 a 46 referem-se aos pequenos centros de armazenamento e triagem (cooperativas); **0 símbolo “-” indica que a respectiva faixa de capacidade ultrapassa o limite identificado para as cooperativas citadas e consequentemente não devem ser considerada. 


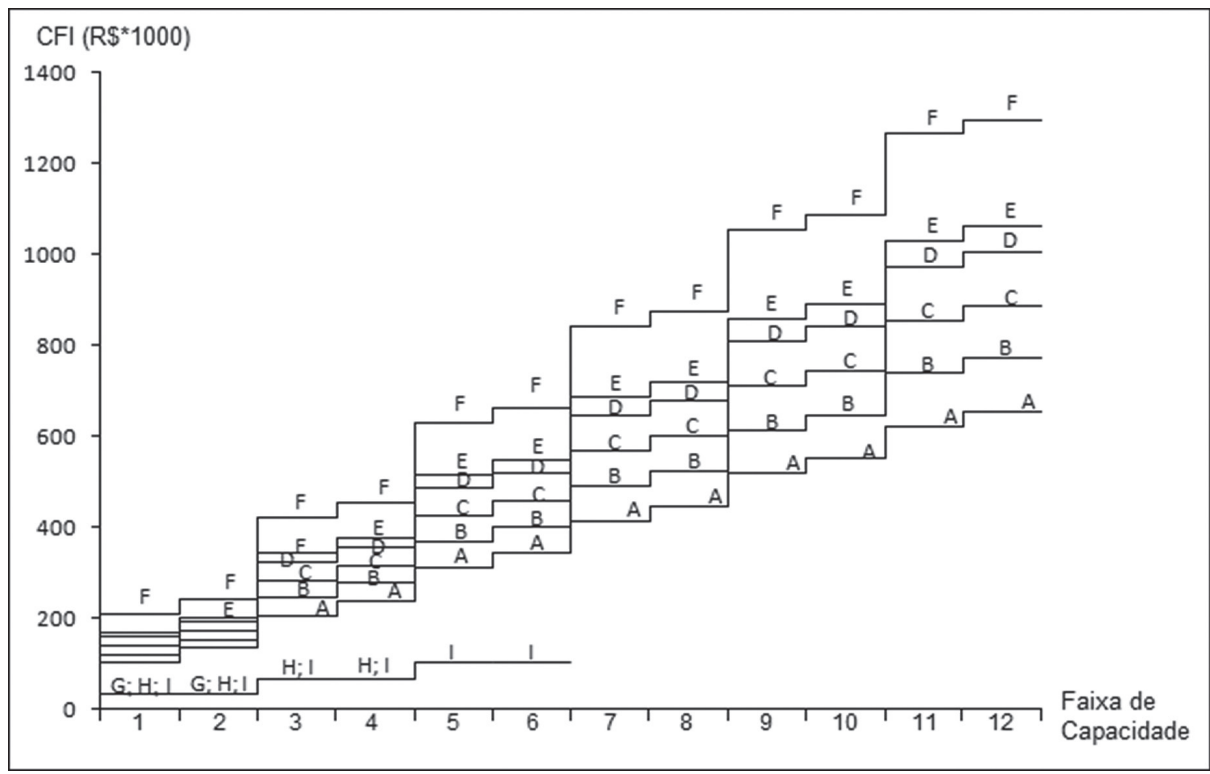

Figura 3. Comportamento do parâmetro custo fixo de instalação por faixa de capacidade. Obs.: Os bairros cujo custo fixo de instalação são similares foram agrupados em: grupo A (1, 2, 3, 4, 5, 6, 8, 9, 11,13, 14, 15, 16, 17, 18, 24, 26, 27, 38), grupo B $(22,28,33,35,36)$, grupo C $(7,10,29,30,32,34,37)$, grupo D (12, 19, 21, 23, 25, 31), grupo E (39), grupo F (20), grupo G (40, 41, 42, 44), grupo H (43, 46), grupo 1 (45).

Tabela 4. Custo fixo de operação.

\begin{tabular}{cc}
\hline Faixa & Custo fixo de operação (R\$/Ano) \\
\hline 1 & $54.960,00$ \\
2 & $58.560,00$ \\
3 & $71.712,00$ \\
4 & $75.312,00$ \\
5 & $88.464,00$ \\
6 & $92.064,00$ \\
7 & $105.216,00$ \\
8 & $108.816,00$ \\
9 & $121.968,00$ \\
10 & $125.568,00$ \\
11 & $138.720,00$ \\
12 & $142.320,00$ \\
\hline
\end{tabular}

do município, com alta densidade demográfica e pouca disponibilidade de espaço para instalação dessas facilidades, em que desapropriações seriam necessárias, além de apresentarem um tráfego mais intenso de veículos e com limitação para a passagem de caminhões. Esses fatores compõem os aspectos tangiveis e intangíveis que influenciam as decisões de localização de centros de armazenagem e triagem no município de São Mateus, conforme discutido na seção 2 . 0 cenário 4 mescla tanto a inclusão das cooperativas quanto a retirada de locais não apropriados para a alocação dos centros, ou seja, um cenário com maior possibilidade de atender às demandas do município. Em seguida foi fixado de maneira crescente o número de facilidades abertas para verificar o comportamento das localizações (pontos selecionados, fluxos alocados e custos), compondo os cenários de 5 a 11. Por fim, no cenário 12, determinou-se a abertura de facilidades em todas as cooperativas já existentes, mas não somente no intuito de verificar como essa decisão com preocupações socioeconômicas impactaria a decisão de instalação dos centros de armazenagem e triagem. A Tabela 5 sintetiza todos os cenários considerados.

0 modelo matemático (1)-(10) foi implementado em linguagem $\mathrm{C} / \mathrm{C}++$ e testado com o CPLEX 12.2 (IBM, 2012) em um computador equipado com um processador Intel ${ }^{\circledR}$ Core $^{\mathrm{TM}} 2$ Solo $(1.4 \mathrm{GHz}, 800 \mathrm{MHZ}$ FSB) e 4GB de memória RAM. A Tabela 6 apresenta os resultados do CPLEX para os cenários considerados.

Como exposto na Tabela 6, o cenário 2 apresenta 0 melhor resultado em termos de custo total (soma dos custos de instalação, operação e transporte, envolvendo o gerenciamento dos RSU), mas deve-se ponderar que esse cenário inclui localidades com restrições para a instalação dos centros de armazenagem e triagem, o que não o torna muito indicado, na prática.

Já os cenários 4 e 10, que apresentaram os mesmos resultados, fornecem, além de um custo reduzido quando comparado aos demais, um resultado mais passível de ser considerado na prática, pois inclui as cooperativas já existentes e exclui as localidades com restrições para alocação dos centros. Nesse caso, o resultado do modelo aponta a abertura 
de seis facilidades distintas, com as respectivas faixas de capacidade: Vila Nova (faixa 2), Ribeirão (faixa 2), Residencial Washington (faixa 1), cooperativa do Projeto Araçá no bairro Universitário (faixa 2), cooperativa do Osmar no bairro Ayrton Senna (faixa 4) e cooperativa do Valdecir no bairro Guriri (faixa 2). A Figura 4 apresenta os locais selecionados e a distribuição dos fluxos de RSU. Nesse caso, o modelo aponta a utilização de três cooperativas já existentes: a cooperativa do Projeto Araçá, localizada no bairro Universitário, a cooperativa do Osmar, localizada no bairro Ayrton Senna, e a cooperativa do Valdecir, no bairro Guriri.

Os cenários 9 e 11 também apresentam um resultado, em termos financeiros, relevante. 0 cenário 9

Tabela 5. Cenários utilizados.

\begin{tabular}{cc}
\hline Cenário & Descrição \\
\hline 1 & Todos os bairros são considerados como possíveis \\
candidatos.
\end{tabular}

indica a abertura de cinco centros de armazenamento e triagem nos bairros Vila Nova (faixa 3), Cohab (faixa 2), cooperativa do Projeto Araçá no bairro Universitário (faixa 2), cooperativa do Osmar no bairro Ayrton Senna (faixa 4) e cooperativa do Valdecir no bairro Guriri (faixa 2), conforme Figura 5. Nesse caso, as mesmas cooperativas encontradas nos cenários $4 \mathrm{e}$ 10 também foram indicadas como possibilidades.

0 cenário 11 indica a abertura de sete centros de armazenamento e triagem nos bairros Vila Nova (faixa 2), Ribeirão (faixa 2), Residencial Washington (faixa 1), cooperativa do Projeto Araçá no bairro Universitário (faixa 2), cooperativa do Primo no bairro Bonsucesso (faixa 2), cooperativa do Osmar no bairro Ayrton Senna (faixa 4) e cooperativa do Valdecir no bairro Guriri (faixa 2), conforme Figura 6. Esse cenário apontou a abertura de novas facilidades e do aproveitamento de quatro cooperativas já existentes, aumentando a inserção desses grupos já atuantes na coleta e triagem dos RSU no município.

No cenário 12 , em que a abertura de facilidades em todas as cooperativas existentes foi estabelecida, o resultado do custo total de funcionamento da rede de logística reversa estudada foi mais elevado em comparação com os outros cenários destacados. No entanto, esse resultado deve ser considerado pela administração pública, já que indica uma possibilidade de inserção de todos os agentes já envolvidos hoje na coleta de RSU no município e, conforme já discutido, por apresentar menor impacto socioeconômico para o município. Portanto, um aumento no custo de instalação dessas facilidades pode significar uma redução de gastos em outras soluções assistencialistas ou de inclusão dessa população que sobrevive da coleta de resíduos. Essas ponderações são importantes: conforme Azambuja et al. (2005), decisões envolvendo a gestão de RSU requerem um compromisso com a realidade dos problemas apresentados, pois "[...] de

Tabela 6. Resultados obtidos com o modelo matemático.

\begin{tabular}{|c|c|c|c|c|c|}
\hline Cenários & $\begin{array}{c}\text { Custo fixo de } \\
\text { instalação (R\$/ano) }\end{array}$ & $\begin{array}{l}\text { Custo fixo de operação } \\
\text { (R\$/ano) }\end{array}$ & $\begin{array}{l}\text { Custo variável de } \\
\text { transporte (R\$ano) }\end{array}$ & $\begin{array}{l}\text { Custo total } \\
\text { (R\$/ano) }\end{array}$ & $\begin{array}{c}\text { Número de } \\
\text { facilidades abertas }\end{array}$ \\
\hline 1 & $102.273,50$ & $322.704,00$ & $406.621,36$ & $831.598,86$ & 5 \\
\hline 2 & $62.041,50$ & $322.704,00$ & $411.775,77$ & $796.521,27$ & 5 \\
\hline 3 & $102.273,50$ & $322.704,00$ & $410.437,69$ & $835.415,19$ & 5 \\
\hline 4 & $57.509,50$ & $364.512,00$ & $379.329,97$ & $801.351,47$ & 6 \\
\hline 5 & $77.269,00$ & $142.320,00$ & $1.696 .397,05$ & $1.915 .986,05$ & 1 \\
\hline 6 & $65.846,00$ & $197.280,00$ & $941.425,82$ & $1.204 .551,82$ & 2 \\
\hline 7 & $51.009,50$ & $239.088,00$ & $593.035,67$ & $883.133,17$ & 3 \\
\hline 8 & $59.205,00$ & $280.896,00$ & $473.765,03$ & $813.866,03$ & 4 \\
\hline 9 & $50.368,50$ & $322.704,00$ & $432.368,33$ & $805.440,83$ & 5 \\
\hline 10 & $57.509,50$ & $364.512,00$ & $379.329,97$ & $801.351,47$ & 6 \\
\hline 11 & $57.509,50$ & $406.320,00$ & $345.024,00$ & $808.853,50$ & 7 \\
\hline 12 & $68.009,50$ & $564.000,00$ & $335.086,87$ & $967.096,37$ & 10 \\
\hline
\end{tabular}




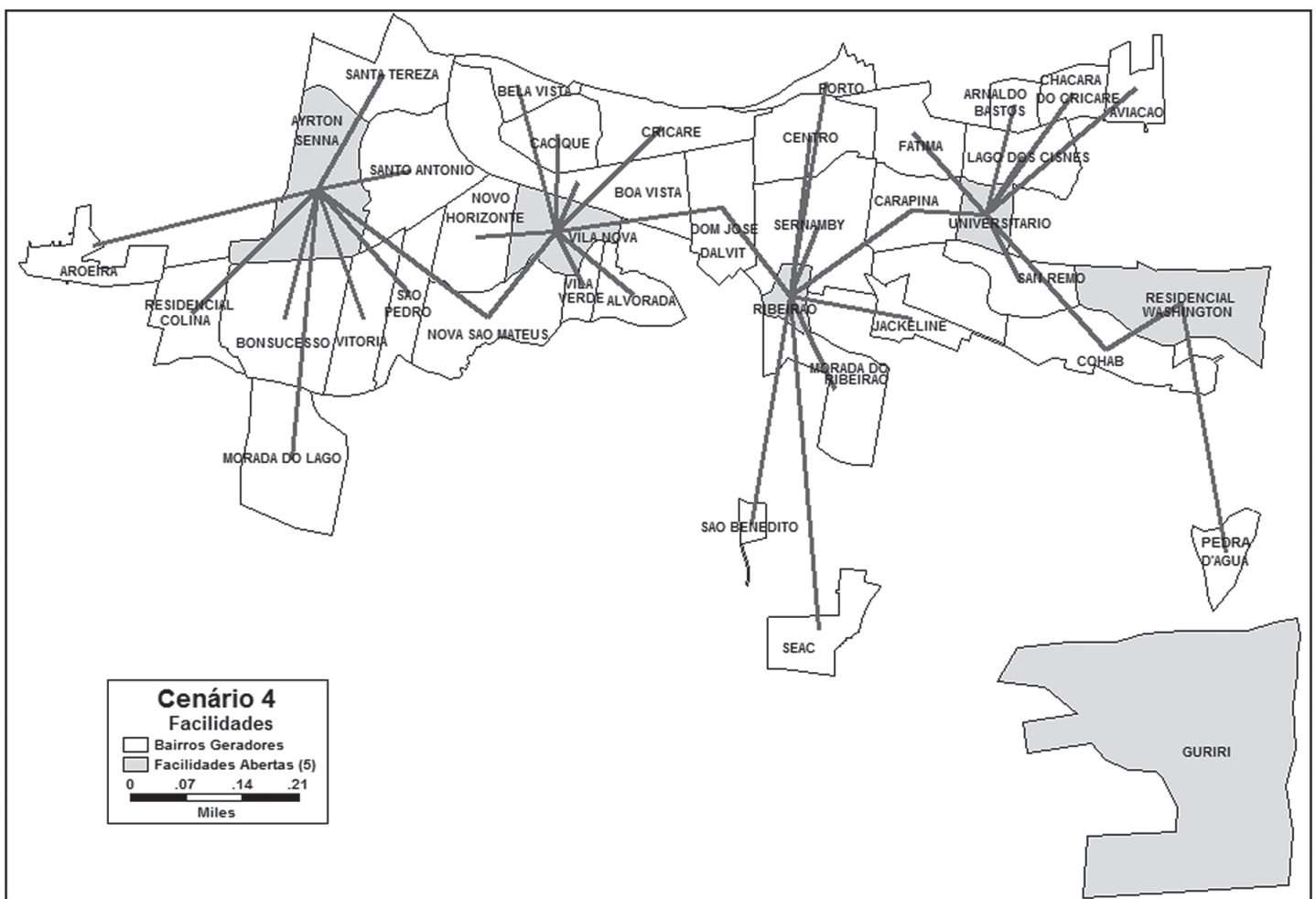

Figura 4. Resultado do cenário 4.

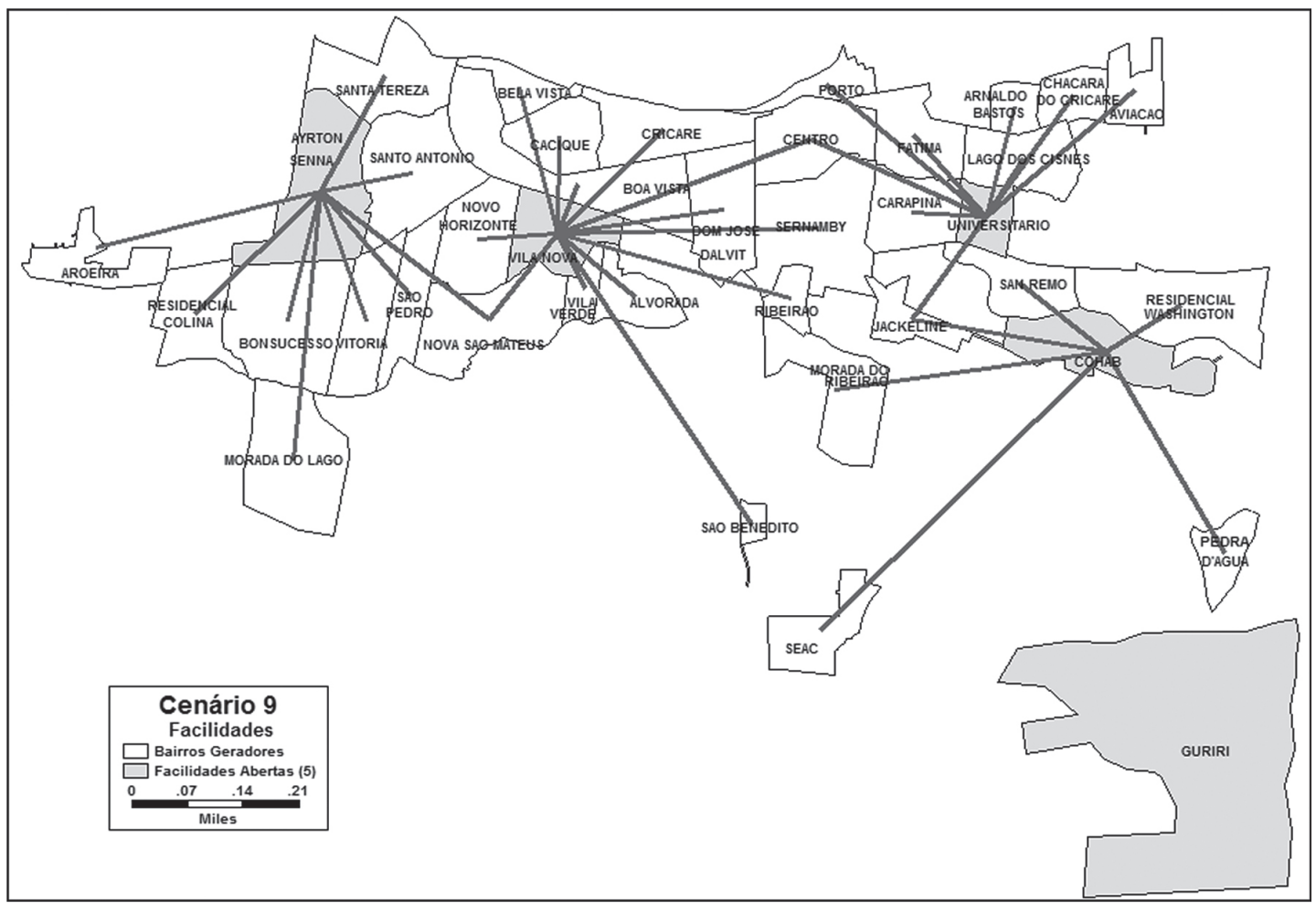

Figura 5. Resultado do cenário 9. 


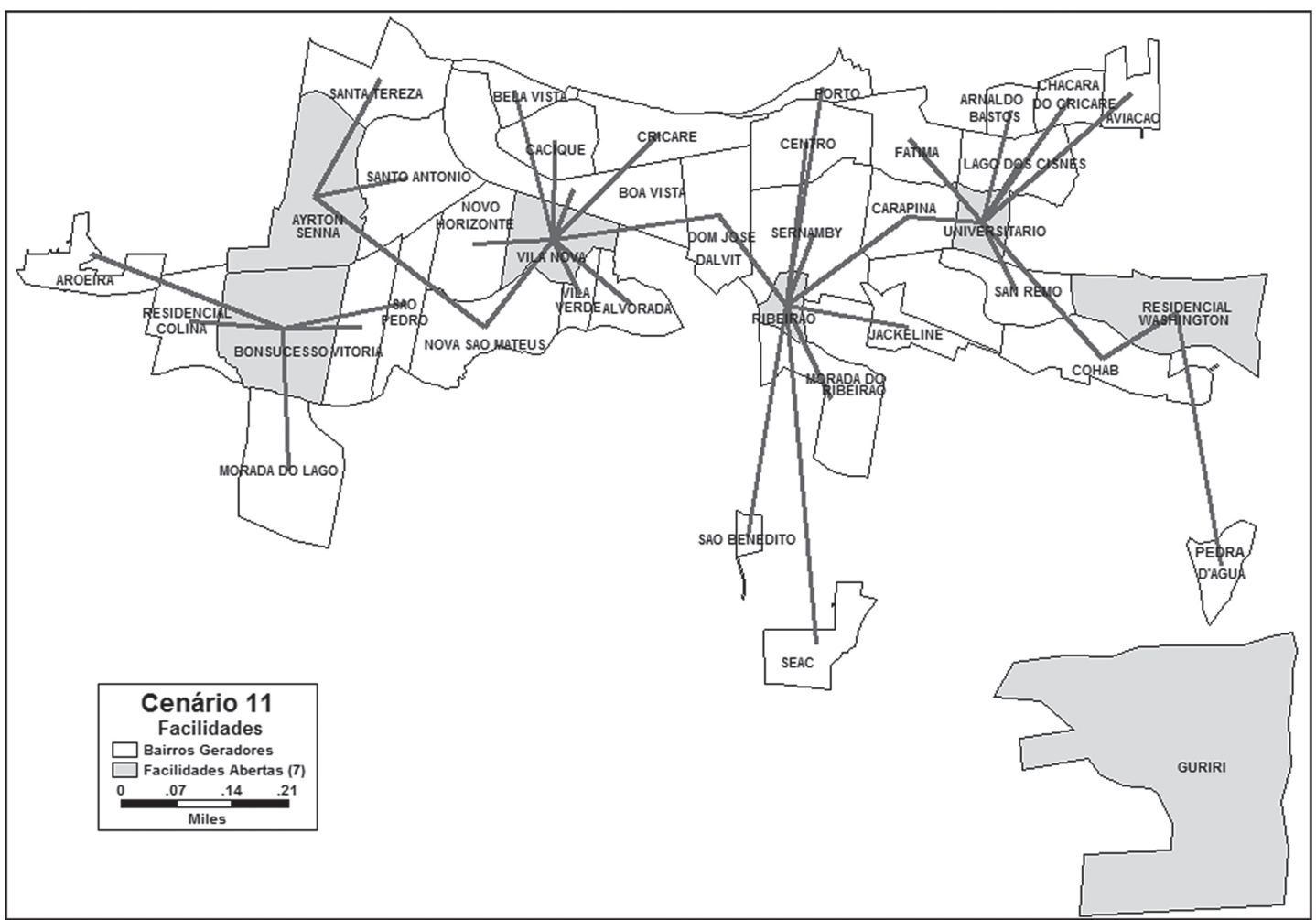

Figura 6. Resultado do cenário 11.

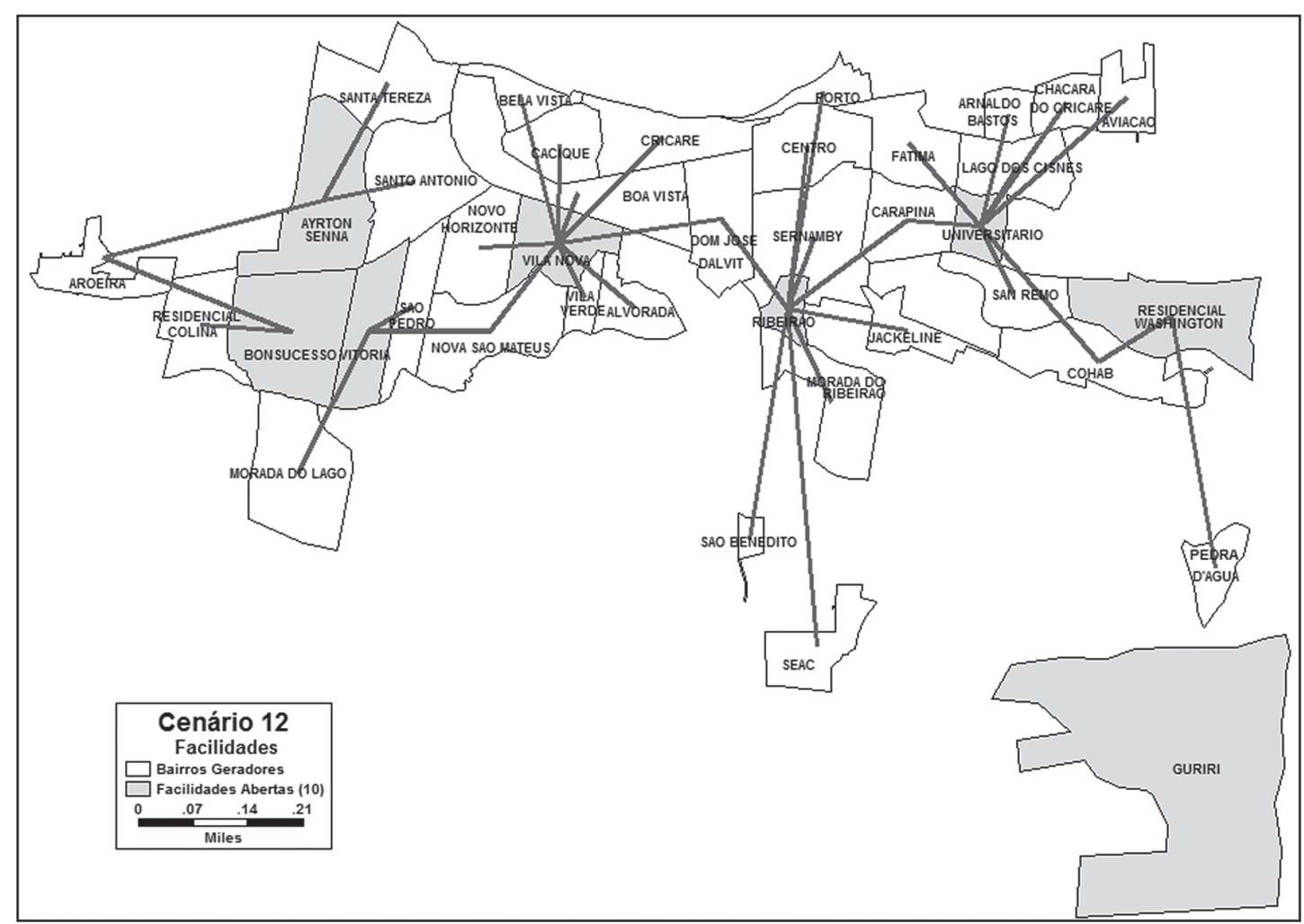

Figura 7. Resultado do cenário 12. 
nada adianta ter um método complexo, sofisticado e que não condiz com a realidade do município." (Azambuja et al., 2005, p. 9) Portanto, esses autores indicam que, além de critérios técnicos, ambientais e econômicos, a gestão de RSU deve considerar o aspecto político das decisões, que envolvem também a aceitação e envolvimento da comunidade, buscando a equidade entre a sociedade.

0 cenário 12 indica a abertura de 10 centros de armazenamento e triagem nos bairros Vila Nova, Ribeirão, Residencial Washington e em todas as cooperativas, conforme a Figura 7.

Os demais cenários, 1, 5, 6, 7 e 8, não apresentaram resultados relevantes em termos de custo ou com restrições, caso do cenário 1 , além de incluir poucas cooperativas já existentes, caso dos cenários 5, 6, 7 e 8 .

\section{Considerações finais}

Este artigo apresentou uma metodologia para municípios baseada em um modelo matemático de localização de centros de armazenamento e triagem de RSU que permite centralizar os resíduos em centros de distribuição reversa. 0 estudo de caso voltado para o munícipio de São Mateus, ES, ilustrou todo o processo de aplicação dessa metodologia.

Os cenários apresentados para o estudo de caso de São Mateus, ES, são resultados da aplicação do modelo matemático e fazem parte do processo de análise. No caso de São Mateus, não se pode afirmar que um cenário é mais correto em detrimento dos demais. Este estudo analisa possibilidades e os custos totais de instalação e operação dos centros de armazenagem e triagem de RSU que devem ser analisados pelo poder público. Essa análise deve ser feita em conjunto com outros aspectos que envolvem toda a rede de logística reversa de RSU no município, tais como a coleta seletiva, a localização do aterro sanitário, assim como as cooperativas envolvidas na coleta de materiais passíveis de reciclagem, escopo que extrapola os objetivos deste estudo.

Os resultados deste estudo poderão ser utilizados pela prefeitura, pois ele fornece informações que auxiliam a tomada de decisão quanto à localização de centros de triagem integrados à coleta seletiva e ao gerenciamento de RSU de forma integrada aos projetos sociais com os catadores de resíduos sólidos. Embora o modelo incorpore especificidades do município de São Mateus, este estudo poderá ser útil a outros pesquisadores e prefeituras, pois a abordagem pode ser estendida a outros setores ou a outras regiões.

Apesar do esforço dos autores em fornecer um modelo matemático que incluísse restrições e características reais de um município, este estudo não abordou aspectos legais de implantação dos centros de armazenagem e triagem de RSU. Esses locais podem receber resíduos caracterizados como perigosos e contaminantes, tais como pilhas e baterias, medicamentos, lâmpadas, dentre outros e, portanto, suas instalações devem seguir a legislação vigente e deve-se evitar aloca-los próximo a locais de grande movimentação de pessoas. Uma limitação deste trabalho é não incluir essa análise, que pode inviabilizar a localização de uma facilidade em um determinado bairro da cidade.

Além disso, assim que determinado o local de construção do aterro sanitário que atenderá ao consórcio dos municípios da região norte do Espírito Santo, o CONORTE, a acessibilidade a esse local deve ser um fator a ser considerado para a definição da localização dos centros de armazenagem e triagem de RSU. Outra questão não verificada foi a possibilidade de alteração do local de atuação das cooperativas, o que certamente influenciaria nos resultados. Portanto, esses fatores devem ser considerados pela administração pública.

Apesar destas limitações, vale ressaltar a flexibilidade do modelo, a ponto de poder passar por alterações sempre que necessário, afinal o volume e as características dos resíduos estão em constante mudança. Segue como sugestão para pesquisas futuras a expansão da modelagem para toda a rede de logística reversa, o que tornaria o modelo mais completo, mas seguindo a orientação de aproximar-se da realidade do gerenciamento dos RSU na região estudada.

\section{Referências}

Adlmaier, D., \& Sellito, M. A. (2007). Embalagens retornáveis para transporte de bens manufaturados: um estudo de caso em logística reversa. Produção, 17(2), 395-406. http://dx.doi.org/10.1590/S0103-65132007000200014

Aquino, l. F., Castilho Junior, A. B. C., \& Pires, T. S. L. (2009). A organização em rede dos catadores de materiais recicláveis na cadeia produtiva reversa de pós-consumo da região da grande Florianópolis: uma alternativa de agregação de valor. Gestão \& Produção, 16(1), 15-24. http://dx.doi.org/10.1590/S0104-530X2009000100003

Araujo, A. C., Matsuoka, E. M., Ung, J. E., Hilsdorf, W. C., \& Sampaio, M. (2013). Logística reversa no comércio eletrônico: um estudo de caso. Gestão \& Produção, 20(2), 303-320. http://dx.doi.org/10.1590/ S0104-530X2013000200005

Associação Brasileira de Empresas de Limpeza Pública e Resíduos Especiais - ABRELPE. (2011). Panorama dos resíduos sólidos no Brasil. São Paulo. Retrieved from http://www.abrelpe.org.br/panorama_apresentacao.cfm.

Azambuja, E., Philippi, D. A., \& Pascale, M. A. (2005). Gestão de resíduos sólidos urbanos: desafios e perspectivas 
para os gestores públicos. In Anais Seminários em Administração, São Paulo.

Ballou, R. H. (2001). Gerenciamento da cadeia de suprimentos: planejamento, organização e logística empresarial. Bookman.

Barcelos, F. B., Pizzolato, N. D., \& Lorena, L. A. N. (2004). Localização de escolas do ensino fundamental com modelos capacitado e não-capacitado: caso de Vitória/ ES. Pesquisa Operacional, 24(1), 133-149. http://dx.doi. org/10.1590/S0101-74382004000100007

Bhatnagar, R., Jayram, J., \& Phua, Y.C. (2003). Relative importance of plant location factors: a cross national comparison between Singapore and Malaysia. Journal of Business Logistics, 24, 147-170. http://dx.doi. org/10.1002/j.2158-1592.2003.tb00035.x

Brasil, Ministério da Justiça. (2010). Institui a Política Nacional de Resíduos Sólidos; altera a Lei no 9.605, de 12 de fevereiro de 1998; e dá outras providências (Lei $n^{\circ} 12.305$, de 02 de agosto de 2010). Diário Oficial da República Federativa do Brasil. Retrieved from http:// www.planalto.gov.br/ccivil_03/_ato2007-2010/2010/lei/ 112305.htm.

Brasil, Ministério do Meio Ambiente. (2012). Planos de gestão de resíduos sólidos: manual de orientação. Brasília: ICLEl.

Chiyoshi, F., Galvão, R. D., \& Morabito, R. (2000). 0 uso do modelo hipercubo na solução de problemas de localização probabilísticos. Gestão \& Produção, 7(2), 146-174. http://dx.doi.org/10.1590/S0104-530X2000000200005

Corrêa, F. A., \& Lorena, L. A. N. (2006). Aplicação da relaxação lagrangeana e do algoritmo genético construtivo na solução do problema probabilístico de localização-alocação de máxima cobertura. Gestão \& Produção, 13(2), 233-244. http://dx.doi.org/10.1590/ S0104-530X2006000200006

Cunha, V., \& Caixeta Filho, J. V. (2002). Gerenciamento da coleta de resíduos sólidos urbanos: estruturação e aplicação de modelo não-linear de programação por metas. Gestão \& Produção, 9(2), 143-161. http://dx.doi. org/10.1590/S0104-530X2002000200004

D’Almeida, M. L. 0., \& Vilhena, A. (Coord.). (2000). Lixo Municipal: Manual de Gerenciamento Integrado. São Paulo: Editora IPT/CEMPRE, 370 p. Volume 2622 de Publicação IPT -Instituto de Pesquisas Tecnológicas do Estado de Sao Paulo, Compromisso Empresarial para Reciclagem.

Dekker, R., Van Wassenhove, L. N., \& Indurfurth, K. (2004). Reverse Logistics. New York: Springer. http://dx.doi. org/10.1007/978-3-540-24803-3

Dubke, A. F. (2006). Modelo de localização de terminais especializados: um estudo de caso em corredores de exportação da soja (Tese de doutorado). Pontifícia Universidade Católica, Rio de Janeiro.

Erengüç, S. S., Simpson, N. C., \& Vakharia, A. J. (1999). Integrated production/distribution planning in supply chains: An invited review. European Journal of Operational Research, 115(2), 219-236. http://dx.doi. org/10.1016/S0377-2217(98)90299-5

Espírito Santo. (2008). Projeto Espírito Santo sem Lixão. Vitória: SEDURB. Retrieved from http://www.sedurb. es.gov.br/download/release $\% 20$ ES\%20sem $\% 20$ lix\%C3\%A3o.PDF

Fleischmanna, M., Bloemhof-Ruwaarda, J. M., Dekkerb, R., Van der Laana, E., Van Nunena, J. A. E. E., \& Van
Wassenhovec, L. N. (1997). Quantitative models for reverse logistics: A review. European Journal of Operational Research, 103(1), 1-17. http://dx.doi.org/10.1016/S03772217(97)00230-0

Geoffrion, A. M., \& Graves, G. W. (1974). Multicommodity distribution system design by benders decomposition. Management Science, 20, 822-844. http://dx.doi. org/10.1287/mnsc.20.5.822

Goetschalckx, M. (2011). Suppy chain models. In: SUPPLY Chain Engineering: International Series in Operations Research \& Management Science. Springer. p. 521-613.

Gouveia, N. (2012). Resíduos sólidos urbanos: impactos socioambientais e perspectiva de manejo sustentável com inclusão social. Revista Ciências \& Saúde Coletiva, 17(6), 1503-1510. http://dx.doi.org/10.1590/ S1413-81232012000600014

Hernandez, C. T., Marins, F. A. S., \& Castro, R. C. (2012). Modelo de gerenciamento da logística reversa. Gestão \& Produção, 19(3), 445-456. http://dx.doi.org/10.1590/ S0104-530X2012000300001

Instituto Brasileiro de Geografia e Estatística - IBGE. (2008). Pesquisa Nacional de Saneamento Básico. IBGE. Retrieved from http://www.ibge.gov.br/home/estatistica/ populacao/condicaodevida/pnsb2008/PNSB_2008.pdf.

Instituto Brasileiro de Geografia e Estatística - IBGE. (2010). Censo 2010: população do Brasil é de 190.732.694 pessoas. IBGE. Retrieved from http://www.ibge.gov.br/ home/presidencia/noticias/noticia_visualiza.php?id noticia $=17662$.

Jayaraman, V., Patterson, R. A., \& Rolland, E. (2003). The design of reverse distribution networks: Models and solution procedures. European Journal of Operational Research, 150(1), 128-149. http://dx.doi.org/10.1016/ S0377-2217(02)00497-6

Klose, A., \& Drexl, A. (2005). Facility location models for distribution system design. European Journal of Operational Research, 162, 4-29. http://dx.doi. org/10.1016/j.ejor.2003.10.031

Krarup, J., \& Pruzan, P. M. (1990). Ingredients of location analysis. In: P. B. Mirchandani \& R. L. Francis (Ed.), Discrete Location Theory (pp. 1-54). New York: John Wiley.

Lopez, R. A., \& Henderson, N. R. (1989). The determinants of location choices for food processing plants. Agribusiness, 5(6), 619-632. http://dx.doi. org/10.1002/1520-6297(198911)5:6<619::AlDAGR2720050607>3.0.CO;2-A

Love, R., Morris, J., \& Wesolowsky, G. (1988). Facility location: models and methods. Amsterdam: North-Holland.

Massukado, L. M. (2004). Sistema de Apoio à Decisão: avaliação de cenários de gestão integrada de resíduos sólidos urbanos domiciliares (Dissertação de mestrado). Universidade Federal de São Carlos, São Carlos.

Melo, M. T., Nickel, S., \& Saldanha-Da-Gama, F. (2009). Facility location and supply chain management: A review. European Journal of Operational Research, 196(2), 401412. http://dx.doi.org/10.1016/j.ejor.2008.05.007

Owen, S. H., \& Daskin, M. S. (1998). Strategic facility location: A review. European Journal of Operational Research, 111(3), 423-447. http://dx.doi.org/10.1016/ S0377-2217(98)00186-6

Pimentel, F. G. (2004). Localização de centros de distribuição em uma cadeia de suprimentos (Dissertação de mestrado). Instituto Militar de Engenharia, Rio de Janeiro. 
Pirkul, H., \& Jayaraman, V. (1998). A multi-commodity, multi-plant, capacitated facility location problem: formulation and efficient heuristic solution. Computers \& Operations Research, 25, 869-878. http://dx.doi. org/10.1016/S0305-0548(97)00096-8

Pizzolato, N. D., Raupp, F. M. P., \& Alzamora, G. S. (2012). Revisão de desafios aplicados em localização com base em modelos da p-mediana e suas variantes. Pesquisa Operacional para o Desenvolvimento, 4, 13-42.

Revelle, C. S., Eiselt, H. A., \& Daskin, M. S. (2008). A bibliography for some fundamental problem categories in discrete location science. European Journal of Operational Research, 184, 817848. http://dx.doi.org/10.1016/j.ejor.2006.12.044

Ribeiro, W. S., \& Arroyo, J. E. C. (2008). Metaheurística GRASP biobjetivo para um problema de localização de facilidades. In Anais do Encontro Nacional de Engenharia de Produção, Rio de Janeiro.
Schwartz Filho, A. J. (2006). Localização de indústrias de reciclagem na cadeia logística reversa do coco verde (Dissertação de mestrado). Universidade Federal do Espírito Santo, Vitória.

\section{Agradecimentos}

Os autores agradecem ao Conselho Nacional de Desenvolvimento Científico e Tecnológico - CNPq (processo 307002/2011-0) e à Fundação de Amparo à Pesquisa do Espírito Santo - FAPES (processo 54689473/2011) pelo apoio financeiro. Os autores ainda agradecem aos revisores anônimos pelas ótimas sugestões fornecidas.

\title{
Analysis and location of urban solid waste collection/inspection centers for a reverse logistics network: a case study in São Mateus-ES
}

\begin{abstract}
The lack of planning in many Brazilian cities that has occurred due to urban population and economic growth has affected public service infrastructure. The collection of urban solid waste (USW) is one of these impacted services and has used open dumps as a short-term solution, causing serious environmental impacts. However, the increase in USW has motivated the Brazilian government to promote a National Solid Waste Policy that aims, among other objectives, to close these open dumps by 2014 and to deploy selective collection, reverse logistics and wet waste composting in Brazil. Landfills must be designed and enabled through the selective collection service. This paper proposes a methodological approach based on a mathematical model to place USW collection/inspection centers that will allow the centralization of waste using reverse distribution centers. A case study was conducted in São Mateus-ES, Brazil, to illustrate the complete data collection and deployment process, which helped to make the model more accurate and to approximate reality to aid public officials' decision-making processes.
\end{abstract}

\section{Keywords}

Urban solid waste. Reverse logistics. Facility location. 